\title{
Chronic diseases among the elderly in a rural Vietnam: prevalence, associated socio-demographic factors and healthcare expenditures
}

\author{
Jonathan Mwangi ${ }^{1 *}$, Asli Kulane ${ }^{1}$ and Le Van $\mathrm{Hoi}^{2}$
}

\begin{abstract}
Background: Globally, the population of elderly persons is increasing as well as the prevalence of chronic diseases. This change is causing increased healthcare costs to health care systems threatening to push many households into poverty. Low and middle income countries are projected to experience the greatest impact from this change. This study aims to describe the prevalence of common chronic diseases (CCDs) among the elderly in Vietnam, the associated socio-demographic factors and healthcare expenditures.

Methods: This is a cross-sectional study in the FilaBavi demographic surveillance site in Vietnam. 2873 persons over 60 years were randomly sampled. Prevalence of CCDs was reported from study subjects who previously were informed by physicians. Healthcare expenditures were determined from recall of expenses during the last hospital visit. Binomial logistic regression was done to determine the socio demographic predictors of having a CCD or multiple CCDs. Mean healthcare expenditures for the elderly with CCDs and those without CCDs were summarised and compared.

Results: Forty two percent of the elderly were found to have at least one CCD. Joint problems were the most common CCD at $35 \%$, followed by hypertension at $15 \%$ and chronic bronchitis at $11 \%$. Being female (OR $=1.51$, $95 \% \mathrm{Cl}=1.03-2.21$, $p$-value $=0.036)$, higher education $(\mathrm{OR}=2.54,95 \% \mathrm{Cl}=1.13-5.74$, $\mathrm{p}$-value $=0.025)$ and having advanced age $(\mathrm{OR}=1.92,95 \% \mathrm{Cl}=1.22-3.00, p$-value $=0.005)$, were associated with common chronic diseases in the elderly. Outpatient healthcare expenditures were found to be significantly higher for the elderly with CCDs than those without CCDs.

Conclusions: Higher education and being female are important key predictors of having a CCD, while wealth quintile is a predictor of multimorbidity, in the elderly. Healthcare expenditures for outpatient health services are higher for elderly persons with CCDs and these costs should be targeted when planning for financial protection.
\end{abstract}

Keywords: Non communicable diseases, Elderly, Socio-demographic, Health expenditure, Vietnam

\section{Background}

Chronic diseases are described by the World Health Organisation, as diseases of long duration and slow progress. They include non communicable diseases such as heart diseases, stroke, cancer, chronic respiratory diseases and diabetes [1]. The definition of an elderly person remains a topic for debate as it varies

\footnotetext{
* Correspondence: jonathanmwangi@gmail.com

${ }^{1}$ Global Health, Department of Public Health Sciences, Karolinska Institute, Widerströmska Huset, Tomtebodavägen 18A, Stockholm, Sweden Full list of author information is available at the end of the article
}

in different societies. It may be associated with the age when a person can start to receive pension benefits. In the high income countries the cut off point is 65 years while the United Nations has an arbitrary cut off of 60 years and above.

The rise in the prevalence and significance of chronic diseases has been attributed to the complex interaction between health, economic growth and development. These diseases have continued to exert tremendous demand on the social welfare and health systems. Chronic diseases have substantially contributed 
to rising healthcare costs [2]. They are also responsible for contributing to decreased productivity in the workplace, prolonged disability and diminished resources within families thereby threatening to push millions into poverty [3]. This is in addition to the physical anguish and reduced quality of life they cause to the patients and their caregivers. Globally chronic diseases currently account for up to 2 in every 3 deaths reported [4], with $80 \%$ of the deaths coming from low and middle income countries [3]. It is also projected that by 2020 the South East Asia and Western Pacific region will have the greatest number of deaths from chronic diseases globally [5].

The global population is ageing, with total number of elderly persons increasing globally. This has been attributed to improvement in healthcare and nutrition. Between 1970 and 2010 the life expectancy at birth rose from 56.4 years to 67.5 years for males and 61.2 years to 73.3 years for females [6]. Globally the proportion of population aged 60 years and above was estimated at $11 \%$ in 2007 and set to rise to over $20 \%$ by 2050 , a process that is described as irreversible [7]. On the other side, increased healthy life expectancy has been accompanied by an increase in the number of healthy years lost to disability due to chronic diseases as ageing increases vulnerability to chronic diseases [8]. This growing elderly population with chronic diseases presents a challenge to healthcare systems due to increased healthcare expenditure $[6,8]$. In Taiwan, expenditures due to chronic diseases among the elderly were up to $90 \%$ of the health expenditure for the elderly, and 5 times higher compared to expenditures for those without chronic diseases [9]. Between these two factors, presence of chronic diseases has been described to have a higher influence on healthcare expenditure than ageing [10]. The increases in healthcare expenditures from the health transition, at household level may expose vulnerable individuals or households to high medical expenditures leading to poverty $[11,12]$.

In Vietnam, the total population has been growing, currently at 87 million, with $6 \%$ being over 65 years old. Crude mortality rates have been falling with a reducing fertility rate currently at 1.9. This has resulted in an ageing population, with the age group over 60 years growing fastest and projected to be $26 \%$ of the population by 2050 . The proportion of chronic diseases in total mortality increased from $41.1 \%$ in 1986 to $61.6 \%$ in 2006. In addition, the incidence of chronic diseases has been shown to increase rapidly especially among elderly people [13]. The most common chronic diseases among the elderly in Vietnam include cardiovascular diseases, joint problems, and chronic pulmonary diseases [14]. Presence of a chronic illness among the rural elderly, in Vietnam has also been shown to be a determinant for the need of care [15] and higher probability of catastrophic health expenditures (when a household's out of pocket health payments equal or exceed $40 \%$ of household income after basic need $s$ have been met) [16]. Other factors include, coming from a poor household and having no health insurance [16]. The elderly in rural Vietnam are thus a vulnerable population, and efforts to offer them financial protection through health care funds for the poor policy have had limited success [17]. Our study aims to describe the prevalence of common chronic diseases (CCDs) among the elderly to monitor the trend of CCDs and describe the healthcare expenditures associated to having CCDs.

\section{Methods}

This is a cross sectional survey study investigating prevalence of CCDs and associated socio-demographic factors and healthcare expenditures. It was a component of a larger study conducted in 2007 in the Fila Bavi Demographic Surveillance site in rural Vietnam. Previously analysed and published papers from the survey data include, remaining life expectancy among older people [18], health-related quality of life and its determinants among older people in Vietnam [19], willingness to pay for formal options of care for community dwelling older people in rural Vietnam [20], and Elderly care activities of daily living in rural Vietnam and its determinants [15].

In 2007, 2240 households with 2873 people aged 60 years and older, were randomly selected from the FilaBavi Demographic Surveillance System (DSS). This represented $50 \%$ of the households with elderly people followed by Fila Bavi. Data was collected by way of questionnaires designed for the study administered to households with elderly persons, through face to face interviews with the elderly or household representatives.

Respondents were asked if they had any of the following common chronic diseases, previously diagnosed by a physician; hypertension, diabetes, cancer, arthritis/osteoarthritis, stroke, angina-pectoris, chronic bronchitis, and cataract. The total number of chronic disease was determined by summation of positive responses for each disease. For each disease, the percentage of positive responses of all responses for that disease was used to determine the prevalence. The prevalence was further aggregated by taking number of positive responses for each elderly person to determine how many suffered from multiple diseases (multimorbidity). These responses were aggregated as those with no disease (no positive response), those with one disease, two diseases and those with 3 or more diseases.

Socio-demographic factors of interest in the study were sex, age, marital status, level of education, whether the elderly person was the head of the household, ethnicity, religion, occupation status and economic situation 
of the household from which a respondent came. Level of education was categorized as illiterate, read and write, primary/secondary school level, high school level and above high school level. These were self reported education levels. The data was further aggregated to those who could read and write only and those who had primary or secondary education or above. Occupation status was categorized as having a job/no job, farmer, worker, officer, or in business. Long term economic situation for the household was determined by classifying the household into 5 wealth quintiles as poorest, poor, middle, richer, richest. Hierarchy among households in FilaBavi based on basic assets was used to determine household wealth quintiles [15]. The 2006-2010 national poverty line for rural areas, based on a monthly per capita income equivalent to VND 200,000 (12.5 American dollars) was used to determine the household poverty status [15].

Healthcare expenditures were determined by asking the respondent to recall the amount of money spent during their last illness episode with a visit to a health facility. Costs were categorised as either incurred during an inpatient visit or for an outpatient visit. Expenditure items include costs for diagnosis and treatment, travel, food and drink, communication and income lost of the accompanying relatives. These costs were reported as direct costs or indirect costs. Direct costs constituted payments made for diagnosis, treatment and medications. Indirect expenditures were those expenses incurred for transport, food and drink, communication as well as income lost during the visit. Mean costs were compared for two groups, those having CCDs and those not having CCDs. To complement healthcare costs, health service utilization was also described, for both inpatient and outpatient.

\section{Statistical analysis}

SPSS version 21 and STATA version 12 software were used for the descriptive and analytical statistical analysis. Socio demographic characteristics of the study population were summarised into proportions. Prevalence of CCDs with corresponding $95 \%$ confidence intervals was computed. Binary logistic regression using the backward stepwise elimination likelihood ratio method was performed. Having a CCD or no CCD, as well as having one $\mathrm{CCD}$ or having more than one $\mathrm{CCD}$ as the outcome variables, and all socio-demographic factors, were the predictor variables. The significance level set at $p<0.05$.

Health care costs were categorised as direct and indirect costs, for both inpatient and outpatient services. They were then summarised using simple means, for those with CCDs and those without CCDs. The mean costs were compared using independent sample $t$-test. The significance level was set at $p<0.05$.
Health service utilization was also described for two groups, those with CCDs and those without CCDs and utilization rates compared using independent samples $t$ test, $p<0.05$.

Ethical approval for the FilaBavi demographic surveillance system, including data on socioeconomic status, was given by the Research Ethics Committee at Umeå University, Sweden (reference number 02-420). The present study was also approved by the Research Ethics Committee at Hanoi Medical University (reference number $51 /$ HMU-RB).

\section{Results}

The socio-demographic characteristics of the study sample are given in Table 1. Proportion of males was lower than that of females. Majority of them was young-old people. Almost one-third of them were widowed or separated. Just over three fifths had primary/secondary education and above. Percentage of elderly who were household heads is higher than those who were household members. Most of older people was belonged to the Kinh - a major ethnic group in Vietnam. The households were equally distributed across the 1st, 2nd, 3rd and 4th wealth quintile, at approximately $21 \%$ for each wealth quintile. When classified by the national poverty line, $85 \%$ of the households were above the national poverty line. Majority of elderly was still working at old ages.

Prevalence of self reported CCDs is as presented in Table 2. Joint problems were the commonest reported CCD, followed by hypertension, chronic bronchitis and cataracts. Cancer and diabetes had very few cases reported, less than $1 \%$ for each. Noted also was the gender difference in the prevalence of the self reported CCDs. Women had twice the prevalence of osteoarthritis compared to men. For self reported chronic bronchitis, men had a higher prevalence compared to women. We also aggregated the prevalence by number of CCDs per person (Table 3). Just over two-fifths of the respondents reported having at least one CCD. Percentage of having more concurrent CCDs sharply decreased when the number of diseases increased.

Mean and proportions for each category are provided in Tables 4 and 5. Results of the binomial logistic regression are presented in Tables 6 and 7. Sex, education and age-group were found to be significant predictors of having CCDs. Females were 1.5 more time likely to have a CCD compared to males. Those having high school education had 2.5 more time likelihood of having a CCD compared to those who were illiterate. Those aged between 75-79 years were 1.9 more times likely to have a CCD compared to those aged 65 years and below.

Among the patients with CCDs, multimorbidity was found to be associated with wealth quintile. The risk of 
Table 1 Socio-demographic characteristics of the study sample

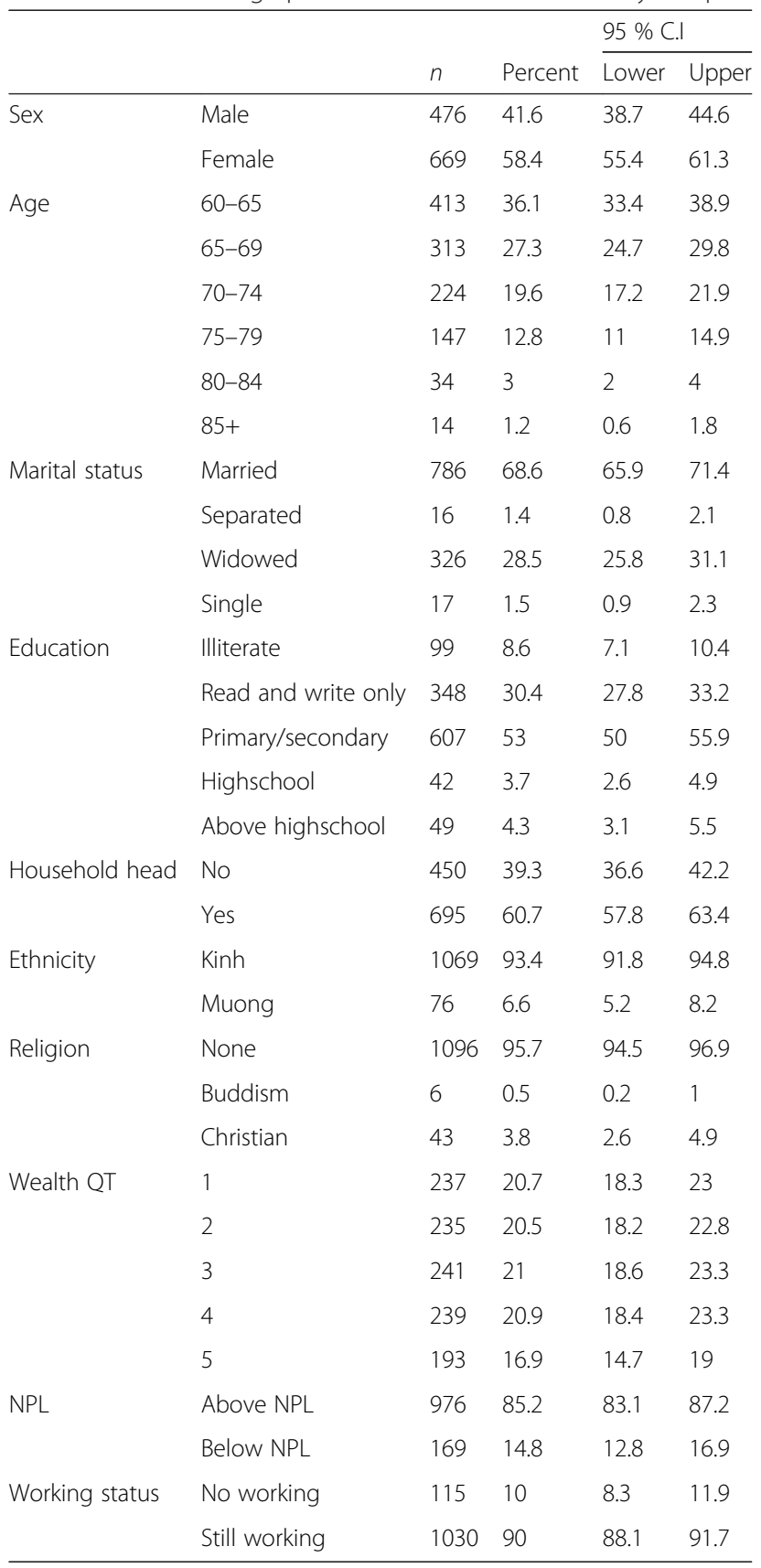

having more than one $\mathrm{CCD}$ for patients in the third wealth quintile (middle), was only $36 \%$ in comparison to the reference group of being in the first wealth quintile (poorest).

Results for health service utilization (Table 8) showed a higher utilization rate for the elderly with CCDs. Results for healthcare costs from those who responded were summarised as simple means (Table 9). All mean expenditures for inpatients were higher, at least 4.5 times, than that of the same items for outpatients. Mean
Table 2 Prevalence of self reported CCDS

\begin{tabular}{llll}
\hline & \multicolumn{2}{l}{ CCD prevalence } & \\
\cline { 2 - 3 } & Male & Female & Total \\
& $\begin{array}{l}\text { Percent } \\
(95 \% \text { c.i) }\end{array}$ & $\begin{array}{l}\text { Percent } \\
(95 \% \text { c.i) }\end{array}$ & $\begin{array}{l}\text { Percent } \\
(95 \% \text { c.i) }\end{array}$ \\
\hline Hypertension & $16(13-18)$ & $14(13-16)$ & $15(13-16)$ \\
Diabetes & $0(0-1)$ & $0(0-1)$ & $0(0-1)$ \\
Arthritis/osteoarthritis & $23(21-26)$ & $41(39-43)$ & $35(33-36)$ \\
Stroke & $3(2-5)$ & $1(1-2)$ & $2(2-3)$ \\
Angina pectoris & $5(3-6)$ & $3(2-4)$ & $4(3-4)$ \\
Chronic bronchitis & $15(12-17)$ & $9(7-10)$ & $11(10-12)$ \\
Cancer & $0(0-0)$ & $0(0-0)$ & $0(0-0)$ \\
Cataract & $3(2-5)$ & $6(5-7)$ & $5(4-6)$ \\
\hline
\end{tabular}

expenditures for outpatient for those with CCDs was higher than that for those without CCDs.

\section{Discussion}

Overall, there was an increase of the prevalence of chronic diseases in the elderly with $42.1 \%$ reporting at least one chronic disease compared to 39.6 previously reported [14]. This could be a pointer to improving healthcare system that is allowing access to chronic care, allowing people to live longer with chronic diseases. However it is also noted that in this study, the prevalence of CCDs was lower from $47.7 \%$ for the 75-79 age group to $42 \%$ for those aged over 85 years. This may indicate mortality from CCDs, leaving those without CCDs to live longer; consistent with a previous conclusion that mortality from CCDs reduces the life expectancy [21]. This interaction, of increased life expectancy and increased mortality from chronic diseases is expected to continue as the country goes through the transition. But perhaps a key issue to note is that mortality from CCDs is higher among those with low socioeconomic status, and low education level $[18,21-23]$, while life expectancy rises among those with higher wealth status, leading to inequalities in life expectancies [18]. It is this growing inequality that should remain the focus area of policies that aim to bridge this gap.

Table 3 Aggregated self reported CCD prevalence

\begin{tabular}{lllll}
\hline & $95 \%$ C.I & & & \\
\cline { 2 - 5 } & $\mathrm{n}$ & Percent & Lower & Upper \\
\hline None & 1662 & 57.9 & 56.1 & 59.7 \\
One & 841 & 29.3 & 27.8 & 31.1 \\
Two & 265 & 9.2 & 8.2 & 10.3 \\
3 or more & 100 & 3.5 & 2.8 & 4.1 \\
\hline
\end{tabular}


Table 4 Mean or Proportion of cases in each category

\begin{tabular}{|c|c|c|c|}
\hline & & No CCD & With CCD \\
\hline Age & & 71.88 & 72.89 \\
\hline \multirow[t]{2}{*}{ Sex } & Male & $37.30 \%$ & $35.80 \%$ \\
\hline & Female & $62.70 \%$ & $64.20 \%$ \\
\hline \multirow[t]{4}{*}{ Marital status } & Married & $55.90 \%$ & $53.10 \%$ \\
\hline & Separated & $1.00 \%$ & $1.40 \%$ \\
\hline & Widowed & $41.90 \%$ & $44.10 \%$ \\
\hline & Single & $1.30 \%$ & $1.30 \%$ \\
\hline \multirow[t]{5}{*}{ Education } & Illiterate & $18.20 \%$ & $17.90 \%$ \\
\hline & Read and write only & $34.60 \%$ & $36.10 \%$ \\
\hline & Primary/secondary & $40.60 \%$ & $37.00 \%$ \\
\hline & High school & $2.70 \%$ & $3.30 \%$ \\
\hline & Above high school & $3.90 \%$ & $5.70 \%$ \\
\hline \multirow[t]{2}{*}{ Head of household } & No & $48.00 \%$ & $47.80 \%$ \\
\hline & Yes & $52.00 \%$ & $52.20 \%$ \\
\hline \multirow[t]{3}{*}{ Ethnicity } & Kinh & $96.50 \%$ & $95.90 \%$ \\
\hline & Muong & $3.50 \%$ & $3.90 \%$ \\
\hline & Other & $0.00 \%$ & $0.20 \%$ \\
\hline \multirow[t]{3}{*}{ Religion } & None & $96.00 \%$ & $96.00 \%$ \\
\hline & Buddism & $1.60 \%$ & $0.70 \%$ \\
\hline & Christian & $2.40 \%$ & $3.20 \%$ \\
\hline \multirow[t]{5}{*}{ Wealth Qt. } & 1 & $17.70 \%$ & $16.80 \%$ \\
\hline & 2 & $17.70 \%$ & $16.60 \%$ \\
\hline & 3 & $23.60 \%$ & $20.10 \%$ \\
\hline & 4 & $21.60 \%$ & $23.10 \%$ \\
\hline & 5 & $19.30 \%$ & $23.40 \%$ \\
\hline \multirow[t]{2}{*}{ NPL } & Above NPL & $84.60 \%$ & $85.80 \%$ \\
\hline & Below NPL & $15.40 \%$ & $14.20 \%$ \\
\hline \multirow[t]{2}{*}{ Working status } & No job & $10.80 \%$ & $9.40 \%$ \\
\hline & Have job & $89.20 \%$ & $90.60 \%$ \\
\hline
\end{tabular}

Sex, education and age have been described in studies before as predictors of chronic illness in Vietnam [2426] and other Asian countries [27]. In this study, men generally had higher prevalence of cardiovascular diseases. They also had a higher prevalence of chronic bronchitis. This higher prevalence among the men is probably attributable to the prevalence of higher risk factors for these diseases among the men [14]. Females had a much higher prevalence of joint problems at $41 \%$ compared to the males at $23 \%$ and this increase in the overall odds of females having a CCD compared to males needs further studies to be done.

Level of education, has been found to have an inverse relationship with the prevalence of chronic illness [14, 28]. In contrast, education has a positive relation to good health outcomes as well as reduced mortality rates
Table 5 Mean or Proportion of cases within each category

\begin{tabular}{|c|c|c|c|c|}
\hline & & No CCD & $1 \mathrm{CCD}$ & $\geq 2$ CCDs \\
\hline Age & & 71.88 & 72.83 & 73.04 \\
\hline \multirow[t]{2}{*}{ Sex } & Male & $37.30 \%$ & $35.40 \%$ & $36.70 \%$ \\
\hline & Female & $62.70 \%$ & $64.60 \%$ & $63.30 \%$ \\
\hline \multirow[t]{4}{*}{ Marital status } & Married & $55.90 \%$ & $52.70 \%$ & $54.00 \%$ \\
\hline & Separated & $1.00 \%$ & $1.30 \%$ & $1.70 \%$ \\
\hline & Widowed & $41.90 \%$ & $44.40 \%$ & $43.50 \%$ \\
\hline & Single & $1.30 \%$ & $1.60 \%$ & $0.80 \%$ \\
\hline \multirow[t]{5}{*}{ Education } & Illiterate & $18.20 \%$ & $18.90 \%$ & $15.60 \%$ \\
\hline & Read and write only & $34.60 \%$ & $34.80 \%$ & $38.90 \%$ \\
\hline & Primary/secondary & $40.60 \%$ & $38.00 \%$ & $34.50 \%$ \\
\hline & High school & $2.70 \%$ & $2.70 \%$ & $4.70 \%$ \\
\hline & Above high school & $3.90 \%$ & $5.50 \%$ & $6.30 \%$ \\
\hline \multirow[t]{2}{*}{ Head of household } & No & $48.00 \%$ & $48.20 \%$ & $46.80 \%$ \\
\hline & Yes & $52.00 \%$ & $51.80 \%$ & $53.20 \%$ \\
\hline \multirow[t]{3}{*}{ Ethnicity } & Kinh & $96.50 \%$ & $95.10 \%$ & $97.80 \%$ \\
\hline & Muong & $3.50 \%$ & $4.60 \%$ & $2.20 \%$ \\
\hline & Other & $0.00 \%$ & $0.20 \%$ & $0.00 \%$ \\
\hline \multirow[t]{3}{*}{ Religion } & None & $96.00 \%$ & $95.80 \%$ & $96.40 \%$ \\
\hline & Buddism & $1.60 \%$ & $1.00 \%$ & $0.30 \%$ \\
\hline & Christian & $2.40 \%$ & $3.20 \%$ & $3.30 \%$ \\
\hline \multirow[t]{5}{*}{ Wealth Qt. } & 1 & $17.70 \%$ & $16.20 \%$ & $18.40 \%$ \\
\hline & 2 & $17.70 \%$ & $16.60 \%$ & $16.40 \%$ \\
\hline & 3 & $23.60 \%$ & $21.90 \%$ & $16.20 \%$ \\
\hline & 4 & $21.60 \%$ & $22.90 \%$ & $23.30 \%$ \\
\hline & 5 & $19.30 \%$ & $22.40 \%$ & $25.80 \%$ \\
\hline \multirow[t]{2}{*}{ NPL } & Above NPL & $84.60 \%$ & $86.10 \%$ & $85.20 \%$ \\
\hline & Below NPL & $15.40 \%$ & $13.90 \%$ & $14.80 \%$ \\
\hline \multirow[t]{2}{*}{ Working status } & No job & $10.80 \%$ & $8.00 \%$ & $12.90 \%$ \\
\hline & Have job & $89.20 \%$ & $92.00 \%$ & $87.10 \%$ \\
\hline
\end{tabular}

from non communicable diseases [18, 21, 22]. This would in turn be evident from higher prevalence of chronic illness in those with higher education status, in keeping with our study. This further highlights education as a factor of inequity in healthcare [21, 23].

Healthcare expenditures were higher for the patients with CCDs compared to those without. This is in contrast to findings from a study that looked at household out of pocket payments in FilaBavi. The study found expenditures on communicable illness to predominate in household health expenditures [29]. However our study was focused on healthcare expenditures for the elderly as opposed to the entire household and found expenditures due to CCDs to be higher. In India expenditures due to CCDs were up to twice the costs incurred for other diseases [30]. In Vietnam 
Table 6 Logistic regression analysis for having an CCD in relation to socio-demographic factors

\begin{tabular}{|c|c|c|c|c|c|}
\hline \multirow{2}{*}{\multicolumn{2}{|c|}{ Socio-demographic characteristic }} & \multirow{3}{*}{$\frac{\mathrm{OR}}{1.00}$} & \multicolumn{2}{|c|}{$95 \% \mathrm{Cl}$} & \multirow[b]{2}{*}{$p$-value } \\
\hline & & & \multirow[t]{2}{*}{ lower } & \multirow[t]{2}{*}{ upper } & \\
\hline \multirow[t]{2}{*}{ Sex } & Ref. Male & & & & \\
\hline & Female & 1.51 & 1.03 & 2.21 & 0.036 \\
\hline \multirow[t]{5}{*}{ Education } & Ref. Illiterate & 1.00 & & & \\
\hline & Read and write & 1.44 & 0.89 & 2.34 & 0.141 \\
\hline & Primary/secondary & 1.38 & 0.83 & 2.27 & 0.213 \\
\hline & Highschool & 2.54 & 1.13 & 5.74 & 0.025 \\
\hline & Above highschool & 1.93 & 0.89 & 4.18 & 0.096 \\
\hline \multirow[t]{6}{*}{ Age } & $\operatorname{Ref}<65$ & 1.00 & & & \\
\hline & $65-69$ & 1.24 & 0.91 & 1.70 & 0.171 \\
\hline & $70-74$ & 1.32 & 0.92 & 1.92 & 0.129 \\
\hline & $75-79$ & 1.92 & 1.22 & 3.00 & 0.005 \\
\hline & $80-84$ & 0.66 & 0.28 & 1.58 & 0.35 \\
\hline & $85+$ & 0.51 & 0.10 & 2.63 & 0.417 \\
\hline
\end{tabular}

chronic diseases have been described as a determining factor in household health expenditure [14] and constant fees for health services may eventually push households into poverty [29]. In this study, this could be a possibility from the increased outpatient fees paid by the patients with chronic diseases, as well as seeking outpatient services at a higher frequency compared to those no CCD [16].

\section{Limitations}

Recall bias and recall errors are possible limitation to this study. In the study we relied on self reported CCDs that had been physician confirmed to minimise the errors. In comparing the mean costs for the two groups, those having CCDs and those not having CCDs the methodology employed may not give a direct link to the difference in costs being associated with CCDs. Also not all respondents could recall their healthcare expenditures.

From the cross sectional study design, we measure the prevalence of disease or outcome at a point in time and it may be difficult to assess association of the discussed risk factors unless the sequence of events is certain. That is, the exposure precedes the outcome. However, our findings provide results from which we can generate hypothesis for future research.

\section{Conclusion}

Ageing of the population will continue, as an outcome of falling birth rates, improved healthcare systems and socioeconomic status of the population. Prevalence of chronic diseases is expected to increase in this growing
Table 7 Logistic regression ${ }^{a}$ analysis for having one CCD or more than one CCDs in relation to socio-demographic factors

\begin{tabular}{llllll}
\hline & & OR & \multicolumn{3}{c}{95 C.I. } \\
\cline { 5 - 6 } & & & Lower & Upper & p-value \\
\hline Step 1a & NPL(1) & 1.005 & 0.496 & 2.036 & 0.99 \\
Step 2a & age_group(1) & 0.742 & 0.404 & 1.362 & 0.335 \\
& age_group(2) & 0.859 & 0.434 & 1.698 & 0.661 \\
& age_group(3) & 0.835 & 0.397 & 1.758 & 0.635 \\
& age_group(4) & 0.753 & 0.167 & 3.386 & 0.711 \\
& age_group(5) & 1.88 & 0.229 & 15.419 & 0.556 \\
Step 3a & Religion(1) & 0 & 0 & & 1 \\
& Religion(2) & 0.65 & 0.175 & 2.41 & 0.52 \\
Step 4a & Education(1) & 1.1 & 0.452 & 2.681 & 0.833 \\
& Education(2) & 0.904 & 0.364 & 2.246 & 0.828 \\
& Education(3) & 2.103 & 0.555 & 7.959 & 0.274 \\
& Education(4) & 0.607 & 0.142 & 2.589 & 0.5 \\
Step 5a & Head of household(1) & 0.822 & 0.46 & 1.468 & 0.508 \\
Step 6a & Sex(1) & 0.747 & 0.439 & 1.272 & 0.283 \\
Step 7a & Marital status(1) & 4.808 & 0.841 & 27.502 & 0.078 \\
& Marital status(2) & 1.202 & 0.735 & 1.968 & 0.463 \\
& Marital status(3) & 1.106 & 0.205 & 5.97 & 0.906 \\
Step 8a 10b & Ethnicity(1) & 0.593 & 0.231 & 1.526 & 0.279 \\
& Have no job(1) & 0.565 & 0.275 & 1.158 & 0.119 \\
& Wealth_quintile(1) & 0.669 & 0.341 & 1.311 & 0.241 \\
& Wealth_quintile(2) & 0.362 & 0.173 & 0.758 & 0.007 \\
& Wealth_quintile(4) & 0.722 & 0.374 & 1.396 & 0.334 \\
\hline
\end{tabular}

${ }^{a}$ The selection process of the backward stepwise in the regression is shown in the table below, from step 1 to 9 , nine non-significant variables were eliminated and their respect $\mathrm{OR}, \mathrm{Cl}$ and $\mathrm{p}$-value at the time of removal are listed. The final step retains only one explanatory variable in the model, i.e., wealth quintile

elderly population. Education remains a key determinant of good health outcomes in populations and more investment in education to the population should continue. In the broader context of social determinants of health, benefits of sustained economic growth should offer

Table 8 Comparison of health service utilization between those without CCDs and those with CCDs

\begin{tabular}{|c|c|c|c|c|c|c|}
\hline \multicolumn{7}{|c|}{ Independent Samples Test } \\
\hline & & $\mathrm{N}$ & total & $\%$ & $\%$ difference & $p$-value \\
\hline \multirow{2}{*}{$\begin{array}{l}\text { Elderly that } \\
\text { sought outpatient } \\
\text { sevices during } \\
\text { the last } 12 \text { months }\end{array}$} & No CCD & 1041 & 1662 & $63 \%$ & $-19 \%$ & $<0.001$ \\
\hline & With CCD & 965 & 1206 & $82 \%$ & & \\
\hline \multirow{2}{*}{$\begin{array}{l}\text { Elderly that sought } \\
\text { inpatient serives } \\
\text { during the last } \\
12 \text { months }\end{array}$} & No CCD & 81 & 1662 & $5 \%$ & $-8 \%$ & $<0.001$ \\
\hline & With CCD & 157 & 1206 & $13 \%$ & & \\
\hline
\end{tabular}


Table 9 Summary of healthcare expenditure ${ }^{a}$ in VND (currency)

\begin{tabular}{|c|c|c|c|c|c|}
\hline \multirow{2}{*}{ Outpatient costs } & & \multirow[b]{2}{*}{$\mathrm{n}$} & \multirow[b]{2}{*}{ Mean } & \multicolumn{2}{|l|}{$95 \%$ C.I } \\
\hline & & & & Lower & Upper \\
\hline No CCD & Diagnosis and treatment cost & 798 & $94,523.81$ & $77,040.15$ & $114,689.00$ \\
\hline With CCD & Diagnosis and treatment cost & 782 & $142,686.70$ & $114,126.10$ & $173,664.40$ \\
\hline No CCD & total_indirect_outpatient & 818 & $78,722.50$ & $15,024.70$ & $203,987.80$ \\
\hline With CCD & total_indirect_outpatient & 789 & $32,528.52$ & $24,066.90$ & $42,111.31$ \\
\hline No CCD & total cost for outpatient & 846 & $107,005.90$ & $88,316.00$ & $129,847.00$ \\
\hline With CCD & total cost for outpatient & 805 & $194,027.30$ & $154,502.60$ & $239,183.90$ \\
\hline \multicolumn{6}{|l|}{ Inpatient costs } \\
\hline No CCD & Diagnosis and treatment cost & 36 & $559,722.20$ & $198,448.70$ & $1,030,526.00$ \\
\hline With CCD & Diagnosis and treatment cost & 69 & $638,043.50$ & $310,406.10$ & $1,026,176.00$ \\
\hline No CCD & total_indirect_inpatient & 39 & $367,512.80$ & $238,489.10$ & $544,145.00$ \\
\hline With CCD & total_indirect_inpatient & 76 & $346,723.70$ & $223,406.10$ & $517,762.40$ \\
\hline No CCD & total cost for inpatient & 37 & $837,513.50$ & $446,858.50$ & $1,373,579.00$ \\
\hline With CCD & total cost for inpatient & 75 & $1,081,707.00$ & $638,593.80$ & $1,634,392.00$ \\
\hline
\end{tabular}

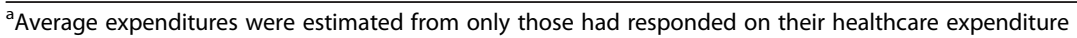

education and employment opportunities to households, as way of enhancing equity in the society in addition to improved healthcare services.

In the face increasing prevalence of chronic diseases and improving healthcare, increased access to healthcare will come with increased household expenditures for healthcare. In particular, our study identifies the elderly persons with chronic diseases as having a higher financial burden compared to those without CCDs thus advocating further attention to this group when offering financial protection. Catastrophic healthcare costs have been described, not commonly as single rare events but rather as continuous costs that eventually grind households into poverty. From our study, this risk is evident from the higher mean costs for outpatient care services for patients with CCDs compared to those without CCDs.

\section{Competing interests}

None.

\section{Authors' contributions}

LVH and JM conceived the study. LVH coordinated the data collection and critically reviewed the manuscript. JM analysed the data and drafted the manuscript. AK participated in the study design, data analysis and reviewed the manuscript. All authors read and approved the final manuscript.

\section{Acknowledgements}

Dr. Le Van Hoi, for facilitating access to data from Elderly Health Project in Fila Bavi, jointly conducted by the Hanoi Medical University and the Umea University, and supported by SIDA and other donors and the Fila Bavi community.

\section{Author details}

${ }^{1}$ Global Health, Department of Public Health Sciences, Karolinska Institute, Widerströmska Huset, Tomtebodavägen 18A, Stockholm, Sweden. ${ }^{2}$ National Lung Hospital, EVIPNet Vietnam, 463, Hoang Hoa Tham, Ba Dinh, Hanoi, Vietnam.

Received: 21 May 2014 Accepted: 8 November 2015

Published online: 17 November 2015

\section{References}

1. Non communicable diseases Fact sheet [http://www.who.int/mediacentre/ factsheets/fs355/en/]

2. Denton FT, Spencer BG. Chronic health conditions: changing prevalence in an aging population and some implications for the delivery of health care services. Can J Aging. 2010;29:11-21.

3. Bloom DE, Cafiero ET, Jané-Llopis E, Abrahams-Gessel S, Bloom LR, Fathima $\mathrm{S}$, et al. The Global Economic Burden of Noncommunicable Diseases. Geneva: World economic forum; 2011.

4. Lozano R, Naghavi M, Foreman K, Lim S, Shibuya K, Aboyans V, et al. Global and regional mortality from 235 causes of death for 20 age groups in, and 2010: a systematic analysis for the Global Burden of Disease Study 2010. Lancet. 1990;2012(380):2095-128.

5. Mathers C, Boerma T, Fat DM. The global burden of disease: 2004 update. switzerland: $\mathrm{WHO} ; 2004$.

6. Salomon JA, Wang H, Freeman MK, Vos T, Flaxman AD, Lopez AD, et al. Healthy life expectancy for 187 countries, 1990?2010: a systematic analysis for the Global Burden Disease Study 2010. Lancet. 2012;380:2144-62.

7. UN: World Population Ageing 2007. 2007 edition; 2007.

8. Holliday R. Ageing in the 21st century. Lancet. 1999;354(Supplement 4):SIV4.

9. Chi MJ, Lee CY, Wu SC. The prevalence of chronic conditions and medical expenditures of the elderly by chronic condition indicator (CCI). Arch Gerontol Geriatr. 2011;52:284-9.

10. Smith KV, Goldman N. Socioeconomic differences in health among older adults in Mexico. Soc Sci Med. 2007;65:1372-85.

11. Whitehead M, Dahlgren G, Evans T. Equity and health sector reforms: can lowincome countries escape the medical poverty trap? Lancet. 2001;358:833-6.

12. Bhojani U, Thriveni B, Devadasan R, Munegowda C, Devadasan N, Kolsteren $\mathrm{P}$, et al. Out-of-pocket healthcare payments on chronic conditions impoverish urban poor in Bangalore. India BMC Public Health. 2012;12:990.

13. L HD: Mortality in transition vietnam. Umea, public health and clinical medicine; 2006.

14. Minh HV, Huong DL, Giang KB. Self-reported chronic diseases and associated sociodemographic status and lifestyle risk factors among rural Vietnamese adults. Scand J Public Health. 2008;36:629-34.

15. Hoi le $V$, Thang $P$, Lindholm L. Elderly care in daily living in rural Vietnam: need and its socioeconomic determinants. BMC Geriatr. 2011;11:81.

16. Van Minh H, Xuan Tran B. Assessing the household financial burden associated with the chronic non-communicable diseases in a rural district of Vietnam. Glob Health Action. 2012;5:1-7.

17. Thanh NX, Lindholm L. Has Vietnam Health care funds for the poor policy favored the elderly poor? BMC Health Serv Res. 2012;12:333.

18. Hoi le V, Phuc HD, Dung TV, Chuc NT, Lindholm L. Remaining life expectancy among older people in a rural area of Vietnam: trends and 
socioeconomic inequalities during a period of multiple transitions. BMC Public Health. 2009;9:471.

19. Hoi le V, Chuc NT, Lindholm L. Health-related quality of life, and its determinants, among older people in rural Vietnam. BMC Public Health. 2010;10:549

20. Van Hoi L, Thi Kim Tien N, Van Tien N, Van Dung D, Thi Kim Chuc N, Goran Sahlen $\mathrm{K}$, et al. Willingness to use and pay for options of care for community-dwelling older people in rural Vietnam. BMC Health Serv Res. 2012;12:36.

21. Huong DL, Van Minh $H$, Janlert U, Van do D, Byass P. Socio-economic status inequality and major causes of death in adults: a 5-year follow-up study in rural Vietnam. Public Health. 2006;120:497-504.

22. Hoang VM, Dao LH, Wall S, Nguyen TK, Byass P. Cardiovascular disease mortality and its association with socioeconomic status: findings from a population-based cohort study in rural Vietnam, 1999-2003. Prev Chronic Dis. 2006;3:A89.

23. Granlund D, Chuc NT, Phuc HD, Lindholm L. Inequality in mortality in Vietnam during a period of rapid transition. Soc Sci Med. 2010;70:232-9.

24. Kaplan GA, Keil JE. Socioeconomic factors and cardiovascular disease: a review of the literature. Circulation. 1993;88:1973-98.

25. Schafer I, Hansen H, Schon G, Hofels S, Altiner A, Dahlhaus A, et al. The influence of age, gender and socio-economic status on multimorbidity patterns in primary care. first results from the multicare cohort study. BMC Health Serv Res. 2012;12:89.

26. Minh HV, Byass P, Chuc NT, Wall S. Gender differences in prevalence and socioeconomic determinants of hypertension: findings from the WHO STEPS survey in a rural community of Vietnam. J Hum Hypertens. 2006;20:109-15.

27. Ahmed SM, Hadi A, Razzaque A, Ashraf A, Juvekar S, Ng N, Kanungsukkasem U, Soonthornthada K, Van Minh H, Huu Bich T: Clustering of chronic noncommunicable disease risk factors among selected Asian populations: levels and determinants. Glob Health Action 2009, 2

28. Van Minh H, Ng N, Juvekar S, Razzaque A, Ashraf A, Hadi A, et al. Self-reported prevalence of chronic diseases and their relation to selected sociodemographic variables: a study in INDEPTH Asian sites, 2005 Prev Chronic Dis. 2008:5:A86.

29. Thuan NT, Lofgren C, Chuc NT, Janlert U, Lindholm L. Household out-ofpocket payments for illness: evidence from Vietnam. BMC Public Health. 2006;6:283.

30. Engelgau MM, Karan A, Mahal A. The Economic impact of Noncommunicable Diseases on households in India. Global Health. 2012;8:9.

\section{Submit your next manuscript to BioMed Central and take full advantage of:}

- Convenient online submission

- Thorough peer review

- No space constraints or color figure charges

- Immediate publication on acceptance

- Inclusion in PubMed, CAS, Scopus and Google Scholar

- Research which is freely available for redistribution 